\title{
Failure Criteria of Artificial Joints: A review
}

\author{
Abdelbary A* \\ Chief Engineer and Tribology Consultant, Egyptian Government, Egypt
}

*Corresponding author: Abdelbary A, Chief Engineer and Tribology Consultant, Egyptian Government, Alexandria, Egypt.

Received Date: October 16, 2019

Published Date: October 30, 2019

\begin{abstract}
Tribology has a significant role in the functioning of artificial joints. The tribological aspects of total artificial replacement joints is reviewed. The basics of tribology are applied to understand the friction, wear and lubrication of natural and artificial joints. The basic wear mechanisms in artificial joint are introduced. Bearing lubrication concepts can be applied to determine the lubrication performance of artificial joints. Major failure criteria of artificial joints, retrieved from patients, are overviewed and discussed. The role of surface and subsurface cracks in polyethylene along with the effect of counterface imperfections in the wear of artificial joints are pointed out. Wear debris are the key factor related with the contacting surfaces of artificial joints which can cause adverse tissue reactions and the loosening of the prosthetic components. In this paper, generation and classification of wear debris are deliberated.
\end{abstract}

Keywords: Tribology; Artificial joint; Failure criteria; Fatigue; Wear debrisr

\section{Introduction}

Artificial joint replacement is one of the most essential arthroplasty for sever diseases of human joints. This surgical treatment involves the replacement of native articulating joints, such as the knee, hip, ankle, and shoulder with artificial components. Currently, it is assumed that there are well over one million artificial joints implanted yearly into patients world-wide $[1,2]$. By 2030, there may be 500, 000 total hip arthroplasty (THA) and 3 million total knee arthroplasty (TKA) cases per year $[3,4]$. Various biomaterial combinations include metals, ceramics, carbon and synthetic polymers are now used in biomedical applications.

In particular, polymeric materials have shown a greatest success in this field due to its excellent tribological properties. Low friction coefficient, high wear resistance, compatibility of wear debris with the body, compatibility of being sterilized by $\gamma$-irradiation, and the facility to operate efficiently for long time under no maintenance conditions are the factors that have made it a highly successful bearing material in these applications [5-8].

For several decades' polyethylene has remained the most suitable material choice for the articulating surface in total joint replacements [9-11]. UHMWPE used as an acetabular cup where the femoral head was stainless steel, ceramic or alumina. UHMWPE was first introduced by Charnley J $[12,13]$ as an alternative for the failed previous polytetrafluoroethylene (PTFE), because the superior wear resistance of the former. A new type of polyethylene material has been developed recently which shown excellent wear properties compared to UHMWPE. This material has been named as ultra-low wear polyethylene (ULWPE). In addition, ULWPE has excellent wear resistance, which is also easy to process [14].

Friction, wear and lubrication of artificial joints play important roles in its successful function. However, it is unpredictable due to complex tribological and biological behaviours and long-term wear [15]. Research efforts are currently addressing the evaluation of the determinants affecting the overall wear rate of the artificial joint articulating surfaces, with the aim of reducing wear rate. However, one of the main challenges is the translation of research data from in vitro to in vivo environments [16]. For example, the wear debris produced by the hip joint simulator has a larger average size and wider distribution range compared to those from the implanted artificial joint [17]. The average diameter of the wear debris from joint simulator is $7.54 \mu \mathrm{m}$. The average diameter of the wear debris from artificial joint is $1.33 \mu \mathrm{m}$ (about 18\% of the wear debris from joint simulator). 
In order to study the failure criteria of artificial joints, a pioneer work was done by Atkinson [13] based on the investigation of a number of worn hip joints ranging in age from 1- 12 years. They observed that the wear and deformation processes of the acetabular cups seemed to be as follows:

1. Initially, a running-in period: the entire cup surface wears abrasively.

2. With increasing mobility, the upper half of the cup wears adhesively.

3. After several years' wear, fine fatigue cracks formed on the wear area.

Many questions which need answering were recognized:

- Are any of the observed wear feature likely to enhance early failure of the acetabular cup or are there other possible mechanisms?

- $\quad$ Are the surface fatigue cracks going to be deletrious? Will they shorten the useable lifetime of the cup?

- What is the effect of the cyclic loading on the failure resistance and surface cracks of the polymeric material specially in fluid lubricated media?

- What is the effect of the generated wear particle size on the clinical infection?

Finally, it was reported that no conclusions could be drawn, and further researches are necessary. For more than four decades, to the best of our knowledge, hundreds of researches were established in order to find answers for those questions. The present paper is aimed to review and argue the failure criteria of artificial joints.

\section{Tribology of Artificial Joints}

Tribology has a significant role in the functioning of artificial joints. General fundamentals of tribology can be used to understand the friction, lubrication and wear of natural and artificial joints in the body [18]. Friction played a dominant role in the design of original Charnley low-friction arthroplasty [19]. Also, wear has an important role, not only from the integrity of the prosthetic component point of view, but also from that of wear debris which can cause adversely biological reactions [15]. Finally, both of friction and wear can be reduced effectively by lubrication.

\section{Friction}

In his low-friction arthroplasty, Charnley, J. introduced the significance of friction in the design of artificial joints [12]. At first, McKee-Farrar introduced metal-on-metal hips. Then, polytetrafluoroethylene (PTFE) was selected for its lowest frictional coefficient, although massive wear was subsequently found with the cups made of this material. Charnley preserved with polymer on metal combinations to maintain low frictional torques and introduced UHMWPE cups sliding on stainless steel femoral heads. This combination of materials has proved to be extremely successful giving low friction, low wear rates of the UHMWPE and smaller amounts of wear debris, which could be more readily tolerated by the body $[10,11,20,21]$.

The following three laws of dry friction are often defined:

1. The force of friction (F) is directly proportional to the applied load (W).

2. The force of friction $(F)$ is independent of the apparent area of contact.

3. The kinetic force of friction $(F)$ is independent of the sliding speed (V).

Kinetic friction is quantified through a coefficient, the coefficient of friction (COF) f, defined as the ratio between the magnitudes of the tangential/friction force $\mathrm{F}$ and the normal force $\mathrm{N}$ at the interface, therefore:

$$
f=\frac{F}{N}
$$

It is worth noting the peculiar behavior of a revolute/spherical joint with frictional contact, shown in Fig. 1 [22]. If we consider a pin rotating within a collar with constant angular velocity $\omega$, under a load $\mathrm{W}$ through the center of the pin itself. In a smooth contact, the equilibrium of the pin is guaranteed by a normal (radial) force $\mathrm{N}=-\mathrm{W}$ applied at the contact point $\mathrm{K}$ on the line of action of $\mathrm{W}$. If friction cannot be neglected, the total contact force at the interface $\mathrm{R}$, still with the same magnitude of $\mathrm{W}$, is the sum of two components $\mathrm{N}$ and $\mathrm{F}$, respectively normal and tangent to the surface at the contact point. Thus, in this case, $\mathrm{K}$ is shifted backwards in an angle $\varphi=\arctan (\mathrm{f})$, so that $\mathrm{R}$ restrains the motion and a torque $\mathrm{M}_{\mathrm{f}}$ must be introduced to maintain the pin rotation (Figure 1).
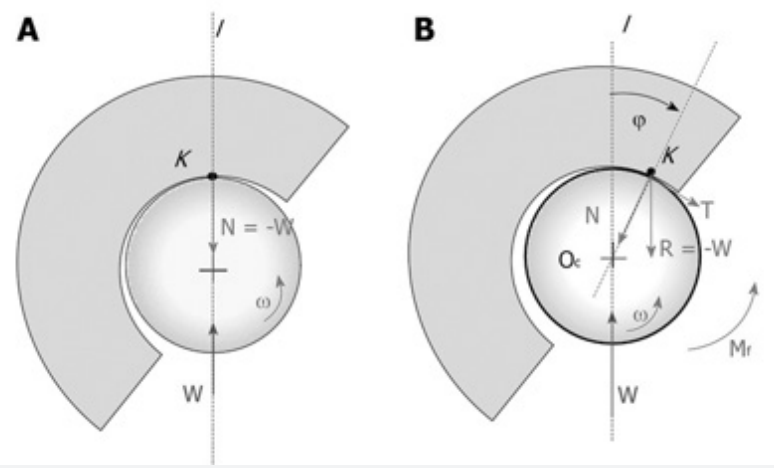

Figure 1: Forces in a revolute/spherical joint: Frictionless $(A)$ and frictional contact (B). Adopted from Francesca Di Puccio et al. [22].

\section{Wear mechanisms}

Wear is recognized as the main reason of implant failure, causing inflammatory reactions and osteolysis, which can lead to implant loosening. The fundamental wear mechanisms in artificial joint are adhesion, abrasion, creep and fatigue. However, pitting, scratching, burnishing and delamination on retrieved total condylar knee joint replacements are also detected [23]. Wear depends on many factors so it can be rather hard to predict which mechanism will affect the 
sliding bodies. This is done usually a posteriori and in many cases several types of wear are detected. The basic wear mechanisms used to describe the wear process in artificial joint replacements are [24]:

Abrasive wear: Abrasive wear is due to the action of hard particles or asperities that plough the softer counterpart. The debris size is of a similar magnitude to the surface roughness of the harder component. Adhesive wear, in which when local welding between asperities occurs, subsequently broken in the movement.

Surface fatigue: Surface fatigue is due to repeated stress cycles in the subsurface material, which can be the onset of microcracks and debris detachment. Fatigue wear can also occur on a macroscopic scale in the form of delamination. This occurs under cyclic loading when the stress applied to the material exceeds the material's fatigue strength [25]. Adhesion and fatigue wear work together, with the surface asperities of the two surfaces momentarily sticking together causing shear stresses that, over time, lead to the eventual fatigue of the asperity; wear particles are generally larger than those that occur in abrasive wear [18].

Pitting: Pitting has long been associated with fatigue damage and commonly has been observed in retrieved implants sterilized with gamma radiation in air, especially tibial plateaus [26]. Pitting was observed in many of the retrieved implants in the present study, suggesting that fatigue wear mechanisms may have been active in these devices. Additionally, some specimens revealed evolution of the machining marks that was suggestive of fatigue crack growth striations, as shown in (Figure 2).

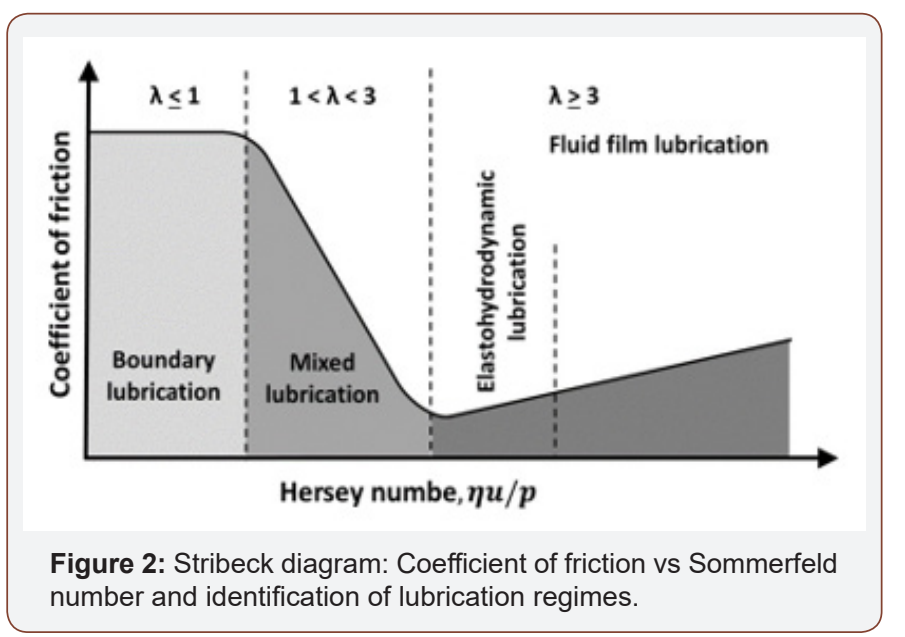

Cooper $[27,28]$ studied the wear of UHMWPE sliding on metallic and ceramic counter faces under wide range of tribological conditions in order to investigate the influence of contact stresses on the macroscopic and microscopic wear mechanisms. The studies were conducted in pin-on-disc and pin-on-plate tribometers, hip joint simulators, and retrieve artificial joints taken from patients. In the body under cyclic loading, the macroscopic polymer asperity is cyclically deformed at the frequency of the loading cycle and this can produce crack propagation and surface fatigue within $10 \mu \mathrm{m}$ of the surface under the polymer asperity. It is likely that cyclic loading is one of the main factors affecting failure of artificial joints. Under dynamic loading conditions found in artificial joints, subsurface cracking was found in the highly strained region. Subsurface crack propagation may well have accelerated the failure and removal of material from the highly strained polymer peaks, hence greatly increasing the macroscopic polymer asperity wear processes. These processes were not only important with respect to the increased volume wear debris produced but may also produce large wear particles which can cause adverse tissue reactions in the body.

\section{Lubrication}

In general, lubrication refers to the existence of a lubricant between two surfaces in contact to avoid or reduce the interaction between their asperities. In healthy natural joints, synovial fluid is generally present as a lubricant. After joint replacements, a pseudo-periprosthetic synovial fluid is found to be similar to those from patients with osteoarthritis [29]. It is important to reduce the contact stresses in order to avoid failure of artificial joints, particularly for thin polymer cups. Effective lubrication, in terms of both boundary and fluid- film lubrication, is the key to reducing friction and wear in artificial joints [19]. The lubrication regime can be assessed either experimentally (ultrasound measurements) or theoretically. The theoretical assessment is based on the determination of the parameter $\lambda$ defined as the ratio between the minimum film thickness $h_{\min }$ and the composite roughness of the two surfaces [30,31]:

$$
\lambda=\frac{h_{\min }}{R_{a}}=\frac{h_{\min }}{\left[\left(R_{a_{-} \text {head }}\right)^{2}+\left(R_{a_{-} \text {cup }}\right)^{2}\right]^{\frac{1}{2}}}
$$

where $R_{a}$ is average roughness. Therefore, if a representative minimum film thickness is estimated and the surface roughness parameters are measured, the lambda ratio and the corresponding lubrication regimes can be determined accordingly:

- Boundary lubrication: $\lambda<1$

- $\quad$ Mixed lubrication: $1<\lambda<3$

- Fluid film lubrication: $\lambda>3$

In joint bearing types, metal on polymer is considered to be boundary lubricated as the relatively soft polymer surface has a high roughness $(\sim 1 \mu \mathrm{m})$, hence surface asperity contact and wear cannot be avoided. Polyethylene does get polished or burnished in vivo which can reduce its roughness, however, the film thickness generated is insufficient to provide significant benefit. Metal on metal joints are generally considered to operate in the mixed lubrication regime. It is suggested that increasing the bearing radii, whilst keeping the radial clearance low, has been shown to increase the predicted film thickness in metal on metal hip prostheses sliding them down the slope of the Stribeck curve (Fig. 2) towards the fluid film lubrication regime [32].

Ceramic on ceramic bearings, compared to metal or polyethylene, are extremely hard and as such can be polished to a very fine surface finish $(\sim 0.004 \mu \mathrm{m}$ Ra). The superior 
manufacturing tolerances of these bearings result in a reduced radial clearance $(\sim 0.04 \mu \mathrm{m})$ which when combined with the low surface roughness leads to a predicted fluid film lubrication regime during walking [33]. In contrast to the former findings, Abdelbary et al. [34] found dramatic increase in the wear rate of Polyamide sliding against stainless steel in water lubrication condition up to about 3 to 6 times those found in dry sliding condition, as shown in (Figure 3).

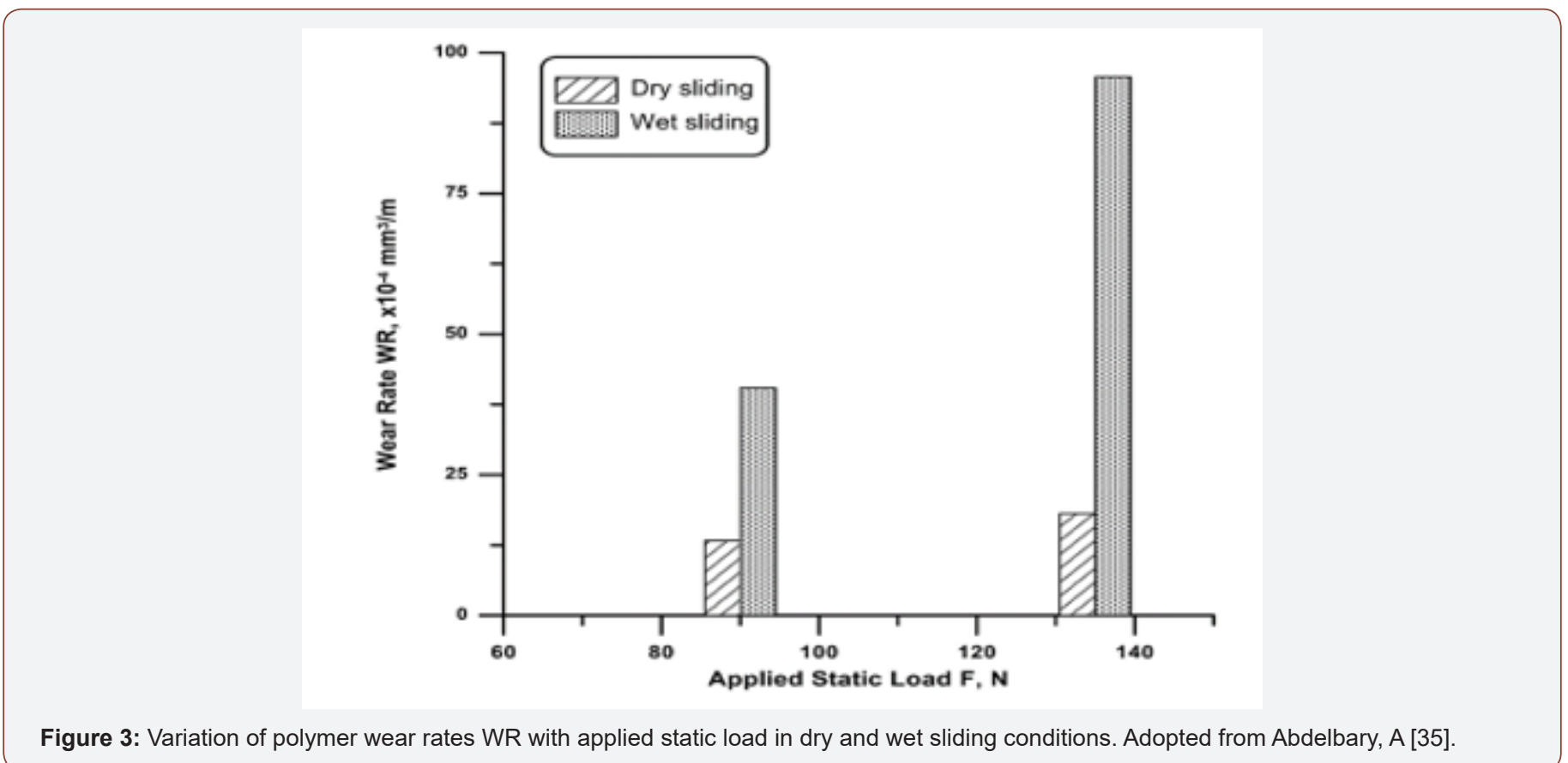

It is suggested that the high wear rates of polyamides are attributed to the plasticization caused by water absorption. The interaction of polymer with water suggests that water molecules diffuse into the polymer surface and loosen the hydrogen bonds between polymer chains, forming hydrogen bonds with amide groups. Consequently, water weakens the intermolecular forces and deteriorates the polymer's mechanical properties. The reduction of attractive forces between polymer chains allows for easy material removal and high wear rate in water lubricated sliding contacts [35].

Another consideration to the effect of water lubricant on the sliding interaction was due to the inhabitation of the formation of transfer films of polymer debris on the counter face. Water scavenges the surfaces of the polymer specimen and the metallic counter face and removes the wear debris from the surface. The washing action of water makes the virgin surface of the polymer is continuously exposed to the counter face. This consideration was typically detected in our present tests, where the wear curves did not show any distinguished running-in phase. It is likely that polymer transfer film, which usually found in dry sliding, failed to form and the slid occurred directly between polymer surface and steel counterpart. Moreover, the water might induce an increase in the chemical corrosion wear of the steel counter faces.

\section{Failure Criteria}

Clinically, the life limit of an implant is when movement becomes so painful that the quality of life of the patient is badly affected [16,36]. It is essential that the root cause of mechanical failure in implants is properly understood. One of the major factors contributing to the failure of total joint replacements is the damage of articulating UHMWPE surfaces. The impact of damaged joint components on patients is widely depicted by Wright, T. M. et al. [37]. Such damage not only affects implant performance, but more importantly results in release of particulate debris to the surrounding tissues and fluids. Damage can be also attributed to fatigue fractures of the metal components and adhesive wear of UHMWPE components [38]. Burger N.D.L. [36, 39] investigated more than 100 retrievals to characterize the failure criteria of implants. The common failures identified are introduced in (Table 1).

Table 1: The common defects observed on the inside of retrieved cups [36].

\begin{tabular}{|c|c|}
\hline Defect Noticed & ISO 12891-3 items [40] \\
\hline Mechanical damage & $\mathrm{a}$ \\
\hline Cracks & $\mathrm{f}, \mathrm{l}$ \\
\hline Scratches & $\mathrm{a}, \mathrm{d}, \mathrm{j}$ \\
\hline Plastic flow & $\mathrm{a}, \mathrm{g}, \mathrm{h}$ \\
\hline Adhesion wear & $\mathrm{a}$ \\
\hline $\begin{array}{c}\text { Wear particles embedded in base } \\
\text { material }\end{array}$ & $\mathrm{a}, \mathrm{c}, \mathrm{e}$ \\
\hline Flaking & $\mathrm{a}$ \\
\hline
\end{tabular}

\section{Mechanical damage}

Mechanical damage (or impingement) is resulted from an acetabular cup not properly aligned in vivo. This damage can also occur after severe wear, when the neck of the femoral component makes contact with the acetabular part. It usually results in pieces of polymer or cement being ripped from the edge of the cup as 
shown in Fig. 4a. The pieces of material removed, therefore, will cause relatively large floating particles and possible loosening of the cup due to impact loading.

\section{Cracks}

Surface and subsurface cracks are usually expected in the high stress areas or on the rim of the cup due to localized stress. Stress cycling and plastic strain accumulate and many surface, and subsurface, cracks are ultimately initiated. With further cycling, these cracks propagate deeply into the substrate or to join their neighbour cracks to create one crack large enough to break from the bulk causing pitting and spalling [11]. The process continues, resulting in a progressive loss of material from the polymer worn surface. The cracks shown in Figure $4 \mathrm{~b}$ are highlighted by means of a color dye penetrant (Figure 4).

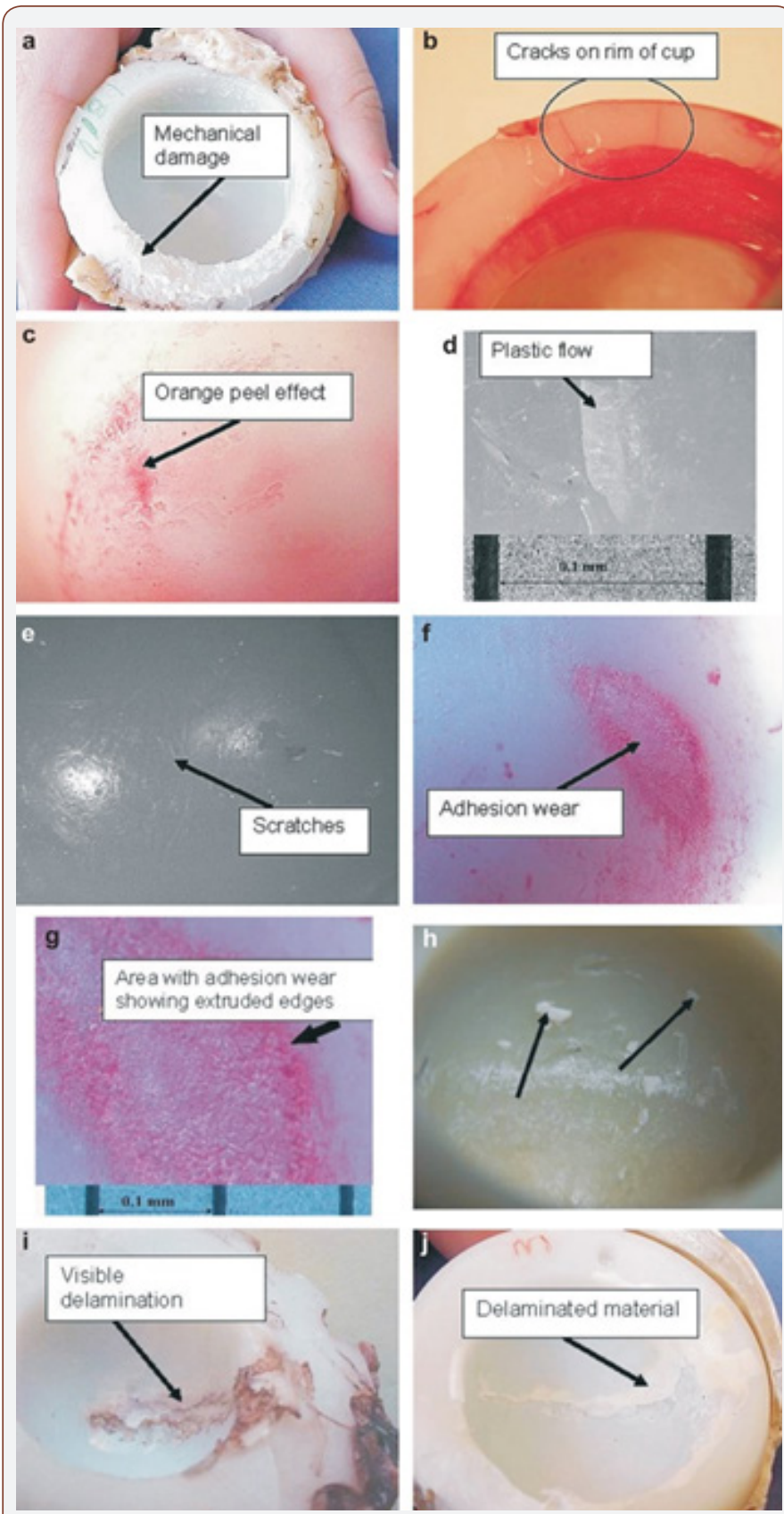

Figure 4: Variation of polymer wear rates WR with applied static load in dry and wet sliding conditions. Adopted from Abdelbary, $A$ [35].
Similar observations were remarked by Letitia et. al. [26], on their study of in vivo wear mechanisms of highly cross-linked UHMWPE. All the retrieved polyethylene acetabular liners that had been examined in their study displayed a surface cracking, as shown in (Figure 5).

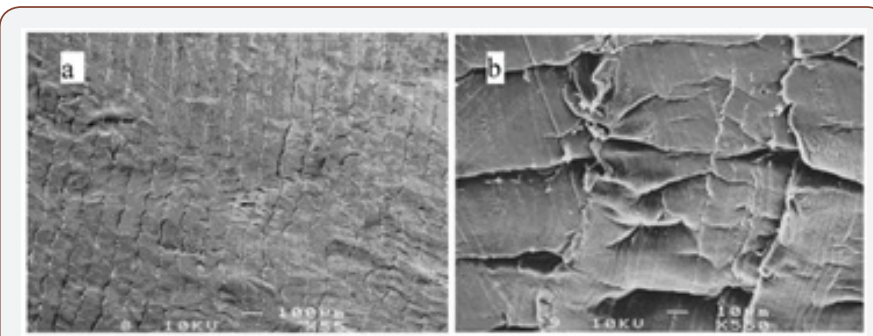

Figure 5: (a) Low-magnification image showing the evolution of altered machining marks and surface cracking parallel to the marks and (b) High-magnification image showing cracking perpendicular to the machining marks. After Letitia et. al. [26].

\section{Scratches}

Some of the examined retrieved components demonstrated evidence of scratching and burnishing on the articulating surfaces [41]. While scratches on a micro scale have been detected, some visible to the naked eye were also present [36]. The comparatively large scratches were due to third-body wear, independent of what caused the wear particles or their type. The appearance of these scratches can be created during the stages shortly after implantation, as shown in Figure 4e. The wear area appeared very smooth and shiny indicating that the surface had been burnished and also some fine scratching in the direction of sliding was present, as shown in (Figure 6).

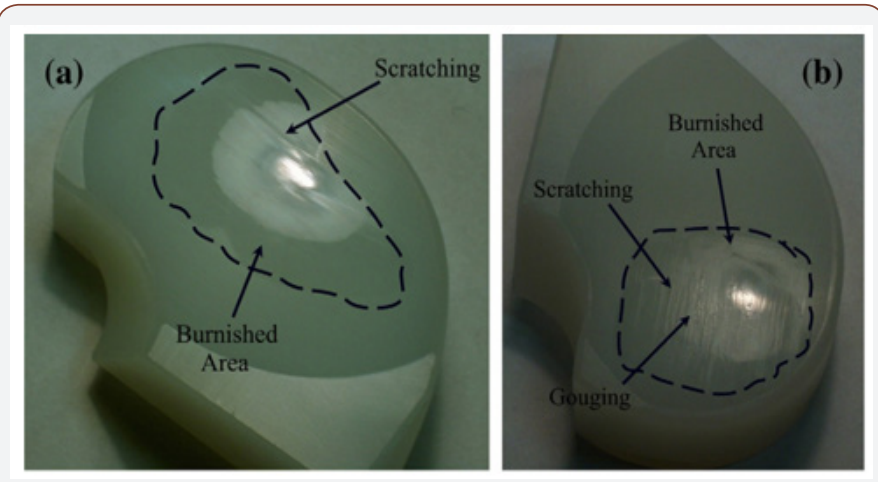

Figure 6: (a) and (b) worn and burnished areas and some slight scratching and gouging of UHMWPE tested in orthopedic wear simulator. Adopted from Flannery, M. et al. [41].

Similar observation was detected in laboratory wear tests of polymer sliding on steel counterface in lubricated conditions [34]. Polymer wear surface appeared relatively smooth and shiny, indicating that the surface had been burnished or lapped. At the end of wear tests, measuring of surface roughness (Ra) of polymer surfaces were found in order of $0.2-0.3 \mu \mathrm{m}$ while roughness of the steel counterface were about 1.3-1.5 $\mu \mathrm{m}$. It is suggested that sliding wear of Polyamide/Steel systems in water lubricant condition results in roughing the steel counterface and smoothing the polymer surface. The former was obviously due to effect of 
rust on the metallic surface, while the later seems to be due to surface lapping effect. Optical microscope investigation of the polymer rubbing surfaces showed very fine scratches in the sliding directions, as shown in (Figure 7).
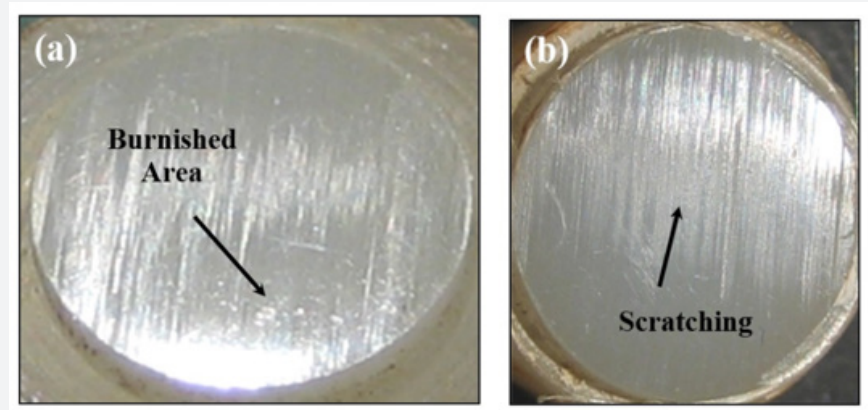

Figure 7: (a) and (b) scratching and burnished area of wear surfaces of polyamide sliding on steel counterface in lubricated conditions. Adopted from Abdelbary, A et al. [34].

\section{Plastic flow}

Optical examination of acetabular cups showed areas of plastic flow, as shown in Fig. 4c and 4d. The affected area normally occurs just outside the region of high contact stress. Visually, it seems as if 'molten' material or polymer softened sufficiently to be extruded was expelled from the area of high contact stress and transferred to one where the stress was less [36]. Furthermore, if the compressive stress on the bearing surface in the cup exceeded the maximum stress limits of the material, it will result in outward flow and/or creep.

\section{Adhesion wear}

Usually, overheating and/or lack of lubrication result in adhesion abrasion wear. This type of wear is normally occurring in the case of limited movement. In such cases, bonding between asperities occurs on two surfaces in contact. Consequent movement causes the asperities of the softer surface to be eliminated. Optical microscopy examination of affected areas showed rough patches and are seen in the high contact stress areas where lubrication was least, as shown in Figure $4 \mathrm{f} \& 4 \mathrm{~g}$.

\section{Flaking}

Flaking arises in areas where pieces of polymer separate from the base material. It presents either as craters or areas of delamination. Serious delamination of two cups are shown in Figure $4 \mathrm{i} 4 \mathrm{j}$. This type of defect is associated with a defect within the material and occurs in the high stress or contact stress areas [36].

\section{Embedded wear particles}

Examination of some of the cups showed wear particles embedded in the base material [36]. Although wear products from the base material were also embedded here, the most common particles found were embedded polymethacrylate (PMMA) cement used for the fixation of the implant as well as polyethylene wear particles. An acetabular cup with PMMA particles embedded is shown in Figure $4 \mathrm{~h}$.

\section{The Role of Surface and Counterface Defects}

The role of counterface imperfections in the wear of polyethylene was investigated by Dowson et. at. [42]. They investigated the influence of single imposed imperfections in stainless steel counterfaces upon the wear of UHMWPE wear pins in linear reciprocating wear test. The imperfections were in the form of either transverse or longitudinal scratches or single indentations, all generated by diamond marks. It has been found that a single transverse scratch can increase the wear rate of the polymer to at least one order of magnitude; the major factor being the piled-up steel along the edge of the scratch. When the piled-up material was removed by remedial lapping, the wear rate returned to its initial value corresponding to the isotropic roughness of the undisturbed counterface. Longitudinal scratches yielded to a less marked yet recognizable increase in the wear rate of the polyethylene. The study supported the views offered previously in explanation of the difference between in vivo and laboratory wear rates of total replacement hip joints.

The effect of a sharp notch on the fatigue behavior of polymers under uniaxial loading and several frequencies was performed by Crawford et al. [43]. It was found that the notch decreased the fatigue of polymers. At the same time a reduction in the heat generated was also observed. Thus, in the presence of a notch, a conventional fatigue failure was observed in polymers under the stresses which would have otherwise produced thermal softening. Furthermore, the fatigue behavior of notched samples was found to be unaffected by variations in test frequency.

\section{Generation and Analysis of Wear Debris}

By definition, wear is a gradual removal of a material from contacting solid surfaces during their relative motion. In any tribosystem, the generation of wear debris is one of the most significant evidences of the wear. Since there are several mechanisms of wear, we should expect that there is no unique or typical form or size of wear debris. In open tribosystems, debris particles can be immediately removed from the sliding contact as loosen particles. Detached debris particles may be involved in a three-body wear; thus it can accelerate the deterioration of the polymer surface due to the wear. On the other hand, in closed tribosystems, wear debris remain circulating into the sliding contact and, consequently, interact to form a polymer transfer film. Almost all prostheses which have been used clinically during the last half century articulate with a boundary or mixed lubrication regime $[11,22,44]$. This allows the bearing surfaces to come into contact, resulting in the generation of wear debris.

Wear and subsequent wear debris are the major issue associated with the bearing surfaces of artificial joints which can cause adverse tissue reactions and the loosening of the prosthetic components. It is widely accepted that the most important roles for bioapplication in the artificial joint is the biocompatibility of wear debris [14]. ULPWE and UHMWPE wear debris generated at the joint surfaces causes macrophage activity, granulomatous tissue 
and necrosis of the bone surrounding the prosthesis [11], as shown in Figure 8 [14].

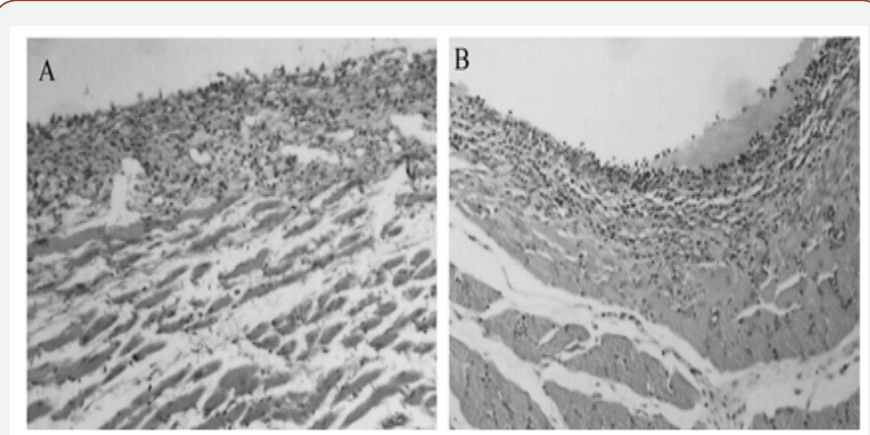

Figure 8: Histopathological observation of the tissue for administration accumulation of wear debris. A: ULPWE group and B: UHMPWE group. After Bian, Y et al. [14].

Experimental studies of the wear of polymers in wet sliding showed that the resulted wear debris are in the form of submicron sized particles [35]. Polymeric wear debris, detected in the lubricating water fluid, were in the form of suspended particles. This scale of wear particles was detected in total hip joints; most UHMWPE wear debris have been shown to be of the micron or submicron size [41,44-46]. Similar size wear debris were, also, produced in hip simulator testing using bovine serum as the lubricant.

In fact, the generation of wear debris in vivo takes place in a closed biological system which cannot be tested and observed directly [47]. Therefore, it is important to carry out the simulating wear test of the artificial joint according to ISO standard. Simulation under conditions that respect real kinematics and dynamics of applying a load to the components are important to predict the tribological behavior of prosthesis. Nevertheless, it is very difficult to simulate the wear behavior of the artificial joint in vivo fully due to the complicated movement process and wear mechanism of the joint friction pair. For example, although the wear loss of materials in vitro conforms to their wear loss under actual conditions, the wear debris from the artificial joint simulator show a different morphology with that in vivo.

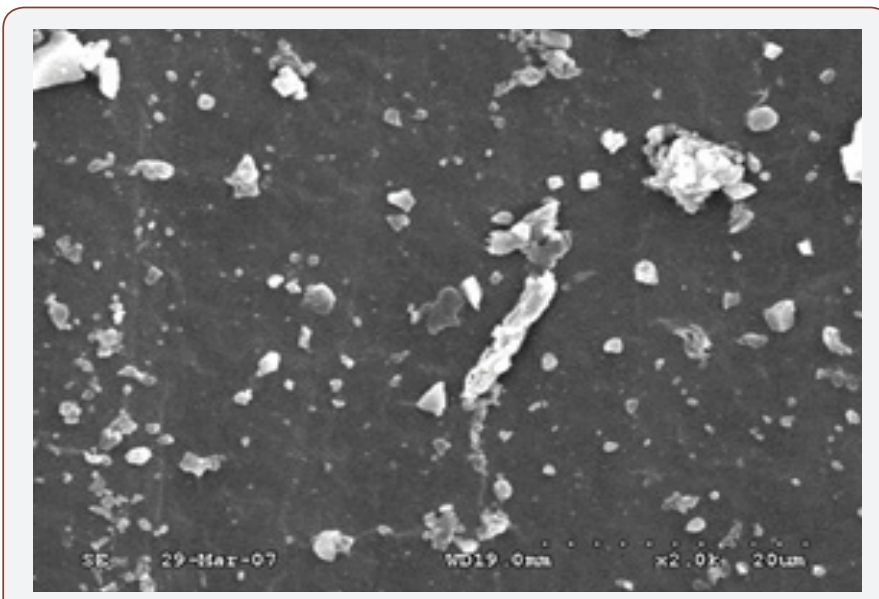

Figure 9: SEM micrograph of UHMWPE wear debris. After Hongtao, L. et al. [17].
Due to the complicated movements of artificial joint, the wear debris of UHMWPE artificial joint in the simulating test shows a variety of morphologies, as shown in Figure 9. It is obvious that the wear debris have different sizes and shapes such as strip, block, plate, and spherical etc. Also, it still can find that the size of wear debris is larger, and the shape is more complicated. When the wear debris is small enough, its shape tends to be spherical or nearspherical [17] (Figure 9).

Typical morphologies of UHMWPE wear debris are shown in Figure 10. The spherical wear debris shown in Fig. 10a has a diameter less than $50 \mu \mathrm{m}$, with wide size distribution and quantity. Spindle or flat block shape as presented in Figure10b, size range is from about $1 \mu \mathrm{m}$ to $50 \mu \mathrm{m}$, is mainly formed in the process of adhesive wear. The wear debris with flat block shape comes from the cracked surface because of the fatigue stress and the separating from wear surface at the weak points by adhesive force. The size of this kind of wear debris is generally above $10 \mu \mathrm{m}$, and the size distribution ranges from $10 \mu \mathrm{m}$ to $150 \mu \mathrm{m}$ (Figure 10).
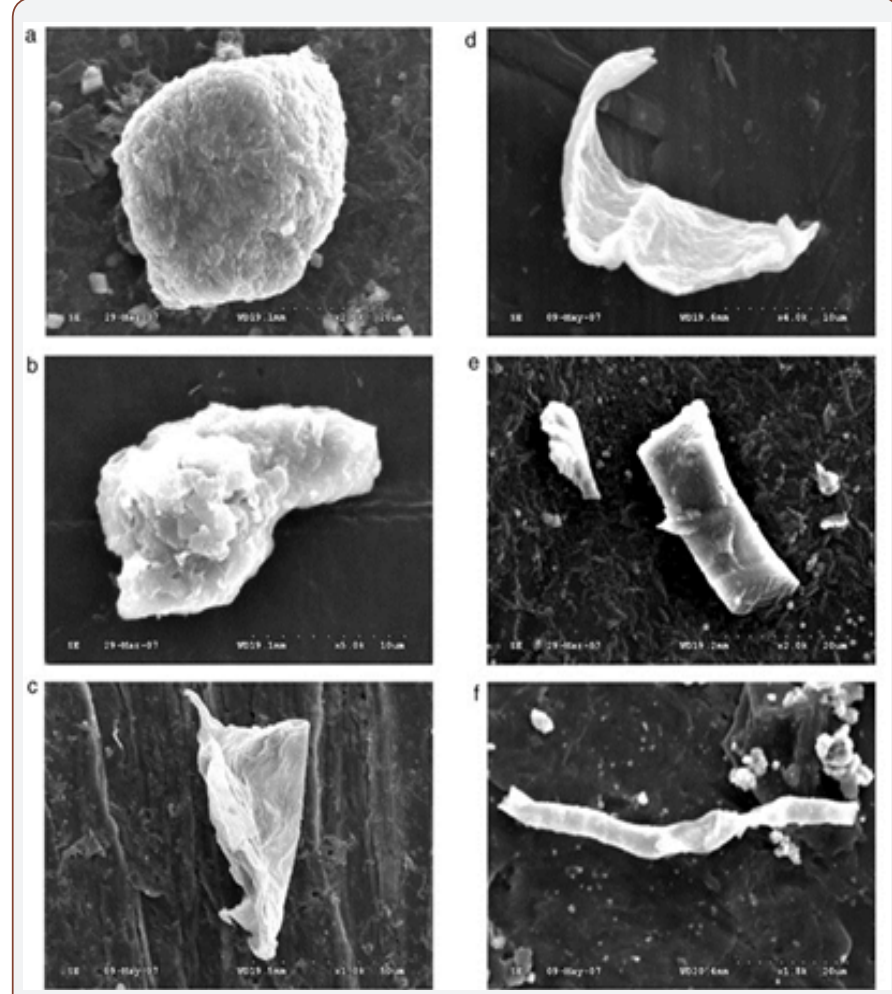

Figure 10: SEM micrograph of UHMWPE wear debris. After Hongtao, L. et al. [17].

Tearing wear debris is the product of composite motion of friction pairs and is the most irregular in all UHMWPE wear debris (Figure 10c). This kind of wear debris has irregular shape, rough surface, and good third dimension. The size of wear debris ranges from about $10 \mu \mathrm{m}$ to $150 \mu \mathrm{m}$. This kind of wear debris produced and grew following the direction of movements of friction pairs and peeling off from wear surface gradually. For different materials and operation conditions, wear debris has different sizes and a wide diameter distribution. Sheet wear debris of a thin thickness and a large plane size is a typical fatigue wear debris as shown in Fig. 10d. This kind of wear debris has a size of about $20 \mu \mathrm{m}$ to $100 \mu \mathrm{m}$. Rod 
wear debris of $10 \mu \mathrm{m}$ to $100 \mu \mathrm{m}$ size has an irregular shape and strong dimensional structure, as shown in Fig. 10e. The occurrence frequency of the wear debris is much less than other kinds. Zonary wear debris is a rare form of artificial joint. Zonary wear debris is generated by kneading sheet wear debris into rope during the test process showing the combined motion state of artificial joint tribology system (Figure 10f).

It is concluded that the wear debris from the artificial joint tester present a different morphology with that from human body, since the morphology of wear debris is an important factor to evaluate artificial joint materials, so we must take the wear debris as one of important parameters for joint simulator design [17].

\section{Conclusion}

In the present paper, the failure criteria of artificial joint are introduced and discussed in light of the cutting-edge literatures. The conclusions are following:

- Friction, wear and lubrication of natural and artificial joints can be studied using the basics of general fundamentals of tribology.

- Surface interaction and wear in artificial joints can be reduced through proper lubrication.

- Mechanical damage, cracks, plastic flow, scratches, wear and flaking are the common modes of failure in artificial joints.

- Wear debris can cause adverse tissue reactions and the loosening of the prosthetic components.

\section{Acknowledgement}

None.

\section{Conflicts of Interest}

No conflicts of interest.

\section{References}

1. Ellen MI, Forbush, Groomes TE (2020) Total Knee Arthroplasty, in Essentials of Physical Medicine and Rehabilitation (Fourth Edition), Frontera WR, Silver JK, Rizzo TD, Philadelphia 443-450.

2. Rizzo TD, (2020) Total Hip Replacement Based on a chapter in the third edition written by In: Juan A, Cabrera, Alison L, Cabrera (Eds.), in Essentials of Physical Medicine and Rehabilitation (Fourth Edition) In: Frontera WR, Silver JK, Rizzo TD (Eds.) Content Philadelphia 337-345.

3. Urban MK, Wolfe SW, Sanghavi NM, Fields K, Magid SK (2017) The Incidence of Perioperative Cardiac Events after Orthopedic Surgery: A Single Institutional Experience of Cases Performed over One Year. HSS Journal 13(3): 248-254.

4. Zawadzki N, Wang Y, Shao H, Liu E, Song C, et al. (2017) Readmission due to infection following total hip and total knee procedures: A retrospective study. Medicine 96(38): e796.

5. In: Sinha SK, Briscoe BJ (Eds.) Polymer Tribology. 2009: Imperial College Press

6. Lu K, LiC, Wang HZ, Li YL,Zhu Y, etal.(2019) Effect of gammairradiation on carbon dot decorated polyethylene-gold@ hydroxyapatite biocomposite on titanium implanted repair for shoulder joint arthroplasty. Journal of Photochemistry and Photobiology B: Biology 197: 111504.
7. Shibata N, Tomita N (2005) The anti-oxidative properties of $\alpha$-tocopherol in $\gamma$-irradiated UHMWPE with respect to fatigue and oxidation resistance. Biomaterials 26(29): 5755-5762.

8. Zhang L, Yoshinori Sawae, Tetsuo Yamaguchi, Teruo Murakami, Hong Yang (2015) Effect of radiation dose on depth-dependent oxidation and wear of shelf-aged gamma-irradiated ultra-high molecular weight polyethylene (UHMWPE). Tribology International, 89: 78-85.

9. Atkinson JR, Dowson D, Isaac JH, Wroblewski BM (1985) Laboratory wear tests and clinical observations of the penetration of femoral heads into acetabular cups in total replacement hip joints: III: The measurement of internal volume changes in explanted Charnley sockets after 2-16 years in vivo and the determination of wear factors. Wear 104(3): 225-244.

10. Dowson D (1985) Influence of Counterface Topography on the Wear of Ultra High Molecular Weight Polyethylene Under Wet or Dry Conditions, in Polymer Wear and Its Control. American Chemical Society 171-187.

11. Fisher J, Dowson D (1991) Tribology of Total Artificial Joints. Proceedings of the Institution of Mechanical Engineers, Part H: Journal of Engineering in Medicine 205(2): 73-79.

12. Charnley JW (1972) The Long-Term Results of Low-Friction Arthroplasty of the Hip Performed as a Primary Intervention. British Orthopedic Association in London 54(1): 61-76.

13. Atkinson JR (1976) The Wear of Total Replacement Hip Joints in the Human Body-A Topgraphical Survey of the Surfaces of Worn Acetabular Cups. in Third Leeds - Lyon Symposium on Tribology.

14. Bian YY, Zhou L, Zhou G, Jin ZM, Xin SX et al. (2018) Study on biocompatibility, tribological property and wear debris characterization of ultra-low-wear polyethylene as artificial joint materials. Journal of the Mechanical Behavior of Biomedical Materials 82: 87-94.

15. Jin ZM, Zhenga J, Lia W, Zhou ZR (2016) Tribology of medical devices. Biosurface and Biotribology 2(4): 173-192.

16. Kashi A, Saha S (2020) 15 - Failure mechanisms of medical implants and their effects on outcomes, in Biointegration of Medical Implant Materials (Second Edition), In: Sharma CP (Ed.) Woodhead Publishing 407-432.

17. Hongtao L, Ge Shirong, Cao Shoufan, Wang Shibo (2011) Comparison of wear debris generated from ultra-high molecular weight polyethylene in vivo and in artificial joint simulator. Wear 271(5): 647-652.

18. Stewart TD (2010) Tribology of artificial joints. Orthopaedics and Trauma 24(6): 435-440.

19. Jin Z, Fisher J (2008) Tribology in joint replacement, in Joint Replacement Technology In: Revell PA, (Ed.) Woodhead Publishing 31-55.

20. Dowson D (1998) History of Tribology. second edition (ed.) U.K: Institution of Mechanical Engineering, London, UK.

21. Zietz C, Reinders J, Schwiesau J, Paulus A, Kretzer JP, et al. (2015) Experimental testing of total knee replacements with UHMW-PE inserts: impact of severe wear test conditions. Journal of Materials Science: Materials in Medicine 26(3): 134.

22. Di Puccio F, Mattei L (2015) Biotribology of artificial hip joints. World journal of orthopedics 6(1): 77-94.

23. Hood RW, Wright TM, Burstein AH (1983) Retrieval analysis of total knee prostheses: A method and its application to 48 total condylar prostheses. Journal of Biomedical Materials Research 17(5): 829-842.

24. Jin Z, Fisher J (2014) Tribology of Hip Joint Replacement, in European Surgical Orthopaedics and Traumatology: The EFORT Textbook In: Bentley G (Ed.) Springer Berlin Heidelberg: Berlin, Heidelberg 23652377

25. Abdelbary A (2014) Fatigue wear of unfilled polymers, in Wear of Polymers and Composites Abdelbary A, (Ed.) Woodhead Publishing: Oxford 67-93.

26. Bradford L, Baker DA, Graham J, Chawan A, Ries MD, et al. (2004) Wear and Surface Cracking in Early Retrieved Highly Cross-linked Polyethylene Acetabular Liners. JBJS, 86(6): 1271-1282. 
27. Cooper JR, Dowson D, Fisher J (1993) Macroscopic and microscopic wear mechanisms in ultra-high molecular weight polyethylene. Wear 162-164: 378-384.

28. Cooper JR, Dowson D, Fisher J, Isaac GH, Wroblewski BM (1994) Observations of residual sub-surface shear strain in the ultrahigh molecular weight polyethylene acetabular cups of hip prostheses. Journal of Materials Science: Materials in Medicine 5(1): 52-57.

29. Yamada H, Morita M, Henmi O, Miyauchi S, Yoshida Y, et al. (2000) Hyaluronan in synovial fluid of patients with loose total hip prosthesis. Archives of Orthopaedic and Trauma Surgery 120(9): 521-524.

30. Elasto hydrodynamic Lubrication, in Tribology Series, GW Sa, Batchelor AW, (Eds.) (1993) Elsevier. 335-424.

31. Jalali-Vahid D, Jagatia M, Jin ZM, Dowson D (2001) Prediction of lubricating film thickness in UHMWPE hip joint replacements. Journal of Biomechanics 34(2): 261-266.

32. Liu F, Jin ZM, Hirt F, Rieker C, Roberts P, et al. (2006) Transient elasto hydrodynamic lubrication analysis of metal-on-metal hip implant under simulated walking conditions. Journal of Biomechanics 39(5): 905-914.

33. Jin Z, Dowson D, Fisher J (1997) Analysis of fluid film lubrication in artificial hip joint replacements with surfaces of high elastic modulus. Proceedings of the Institution of Mechanical Engineers, Part H: Journal of Engineering in Medicine 211(3): 247-256.

34. Abdelbary A, Abouelwafa MN, El Fahham IM, Hamdy AH (2013) The effect of surface defects on the wear of Nylon 66 under dry and water lubricated sliding. Tribology International 59: 163-169.

35. Abdelbary A (2014) Wear of polymers in wet conditions, in Wear of Polymers and Composites, Abdelbary A, (Ed.) Woodhead Publishing: Oxford. 95-112.

36. Burger NDL, De Vaal PL, Meyer JP (2006) Failure criteria for polyethylene acetabular cups. South African Journal of Science 102(11-12): 572-574.
37. Wright TM, Goodman SB (2001) Implant Wear in Total Joint Replacement: Clinical and Biologic Issues, Material and Design Considerations. Rosemont, USA: American Academy of Orthopaedic Surgeons.

38. Rawal BR, Yadav A, Pare V (2016) Life Estimation of Knee Joint Prosthesis by Combined Effect of Fatigue and Wear. Procedia Technology 23: 60-67.

39. Burger NDL, De Vaal PL, Meyer JP (2007) Failure analysis on retrieved ultra-high molecular weight polyethylene (UHMWPE) acetabular cups. Engineering Failure Analysis 14(7): 1329-1345.

40. Retrieval and analysis of surgical implants. Part 3, Analysis of retrieved polymeric surgical implants. 2000: Geneva.

41. Flannery M, Mc Gloughlin T, Jones E, Birkinshaw C (2008) Analysis of wear and friction of total knee replacements: Part I. Wear assessment on a three-station wear simulator. Wear 265(7): 999-1008.

42. Dowson D, Taheri S, Wallbridge NC (1987) The role of counterface imperfections in the wear of polyethylene. Wear 119(3): 277-293.

43. Crawford RJ, Benham PP (1975) Some fatigue characteristics of thermoplastics. Polymer 16(12): 908-914.

44. Zhang D, Liu H, Wang J, Sheng C, Li Z (2018) Wear Mechanism of Artificial Joint Failure Using Wear Debris Analysis. Journal of Nanoscience and Nanotechnology 18(10): 6805-6814.

45. Kowandy C, Mazouz H, Richard C (2006) Isolation and analysis of articular joints wear debris generated in vitro. Wear 261(9): 966-970.

46. Hatton A, Nevelos JE, Nevelos AA, Banks RE, Fisher J, et al. (2002) Alumina-alumina artificial hip joints. Part I: a histological analysis and characterization of wear debris by laser capture microdissection of tissues retrieved at revision. Biomaterials 23(16): 3429-3440.

47. Slouf M, David Pokorny, Gustav Entlicher, Jiri Dybal, Hana Synkova, et al. (2008) Quantification of UHMWPE wear in periprosthetic tissues of hip arthroplasty: Description of a new method based on IR and comparison with radiographic appearance. Wear 265(5): 674-684. 